DOI 10.37882/2223-2982.2020.09.22

\title{
МОТИВАЦИОННОЕ УПРАВЛЕНИЕ ИННОВАЦИОННОЙ ДЕЯТЕЛЬНОСТЬЮ ПРЕПОДАВАТЕЛЕЙ КОЛЛЕДЖА: ТЕОРЕТИЧЕСКИЙ АНАЛИЗ
}

\section{MOTIVATIONAL MANAGEMENT OF INNOVATIVE ACTIVITY OF TEACHERS IN THE COLLEGE: A THEORETICAL ANALYSIS \\ D. Nedostupenko}

Summary: The article discusses the possibilities of motivational management in the formation and development of innovative activities of College teachers. The analysis of research on innovation and management convincingly proves the pedagogical, stimulating, scientific and methodological influence of motivational management on the innovative activity of teachers.

The problem of managing the development of motivation of pedagogical activity is very relevant. Motivational management of innovative activity of College teachers is a process that includes a set of interrelated methods, management tools and conditions necessary and sufficient for the formation of motives for self-development and self-realization in the professional activity of a teacher.

The motivational component is the leading one in the structure of innovation, so motivational management can ensure the harmonious implementation of this activity and self-disclosure of College teachers. The specific activity of the head of the College (education Manager) is aimed at motivating teachers to innovate, self-realization in the professional sphere.

Keywords: motivational management, pedagogical activity, innovative activity of teachers, professional activity of College teachers.
$\Gamma$ лавным фактором инновационной подготовки преподавателя является развитие его личностного потенциала, индивидуального стиля и способности быть субъектом инновационной деятельности, которые формируются средствами внутриколледжного управления. Поэтому представляется важным рассмотреть понятие «управление», выявить его особенности и возможности в развитии инновационной деятельности преподавателей.

Теоретические основы и методы управления наиболее полно представлены в работах Ю.В. Васильева, Ю.А. Конаржевского, А.А. Орлова, М.М. Поташника, П.И. Третьякова, Т.И. Шамовой и других. Опираясь на их исследования, можно выделить три позиции в рассмотрении понятия «управление».

Авторы В.Г. Афанасьев, А.А. Орлов, Н.С. Сунцов, А.В.

\author{
Недоступенко Дарья Александровна \\ Аспирант, ФГБОУ ВО «Белгородский государственный \\ национальный исследовательский университет", \\ Белгород \\ unique-91@bk.ru
}

Аннотация: В статье рассматриваются возможности мотивационного управления в формировании и развитии инновационной деятельности педагогических работников колледжа. Анализ исследований инноватики и менеджмента убедительно доказывает педагогическое, стимулирующее, научно-методическое влияние мотивационного управления на инновационную деятельность преподавателей. Проблема управления развитием мотивации педагогической деятельности очень актуальна. Мотивационное управление инновационной деятельностью преподавателей колледжа - процесс, включающий совокупность взаимосвязанных методов, средств управления и условий, необходимых и достаточных для формирования мотивов саморазвития и самореализации в профессиональной деятельности преподавателя. Мотивационный компонент является ведущим в структуре инновационной деятельности, поэтому мотивационное управление способно обеспечить гармоничное осуществление этой деятельности и самораскрытие преподавателей колледжа. Специфическая деятельность руководителя колледжа (менеджера образования) направленна на мотивирование преподавателей к инновационной деятельности, самореализации в профессиональной сфере.

Ключевые слова: мотивационное управление, педагогическая деятельность, инновационная деятельность преподавателей, профессиональная деятельность преподавателей колледжа.

Филиппов рассматривают управление как воздействие одной системы на другую, одного человека на другого или другую группу, т.е. управление - целенаправленное воздействие субъекта на объект и изменение последнего в результате воздействия. При такой трактовке управления слабо учитывается его «субъект-субъектная природа», поскольку активность признается только за управляющим, а управляемый в данном случае воспринимается как пассивный исполнитель, строго следующий навязанной норме.

Авторы П.И. Третьяков, Т.К. Чекмарева, Т.И. Шамова считают, что управление - активное взаимодействие руководителей образовательной организации и других участников педагогического процесса по его упорядочению и переводу в новое качественное состояние, более отвечающее выполнению поставленных задач [9]. 
В.С. Лазарев, М.М. Поташник рассматривают управление как деятельность по реализации целей организации, целенаправленная деятельность управляющего по согласованию субъект-субъектных отношений и действий для поддержания системы и приведения ее в заданное (программированное) состояние. В нем фиксируются признаки специфической деятельности: функциональный состав (планирование, организация, контроль и руководство), целевое назначение (организованность совместной деятельности участников образовательного процесса и направленность ее на достижение образовательных целей и целей развитая колледжа) и субъект деятельности [3].

В самом общем виде управление предстает как определенный тип взаимодействия, которое характеризуется тем, что субъект управления направляет объекту управления импульсы воздействия (управление команды), а объект управления получает их и функционирует в соответствии с ними. Для того, чтобы управление осуществлялось, необходимо:

- наличие у субъекта управления потребности и возможности управлять объектом, вырабатывая для этого соответствующие (управленческие) решения;

- наличие у объекта управления готовности и возможности эти команды выполнять.

Данные условия являются необходимыми и достаточными для того, чтобы субъект управления осуществлял управление объектом управления [2].

Толкование внутриколледжного управления в последнем варианте, на наш взгляд, в большей степени соответствует реальной управленческой практике. Согласно методологии современного менеджмента, управлять - приводить других к достижению ясной цели, а не заставлять их делать то, что считаешь правильным сам, управлять - приводить к успеху других [4; 6]. Менеджмент рассматривает успех с позиции удовлетворения у человека потребностей высшего уровня в уважении значимыми для личности людьми, в самовыражении через профессиональную творческую деятельность. Немаловажную роль в этом играет мотивация.

Проблема управления развитием мотивации педагогической деятельности являлась предметом исследования многих ученых. Анализ литературы позволил выделить ряд положений, касающихся мотивации и стимулирования педагогической деятельности преподавателей, в основе которых необходимость:

- объединения вокруг определенной фигуры, центра педагогического коллектива - директора (А.С.
Макаренко);

- пробуждения у преподавателей интереса к поиску, к анализу собственной работы (В.А Сухомлинский);

- формирования социально-психологических состояний и свойств, которые необходимы для продуктивной работы (В.С. Лазарев, Р.Х. Шакуров).

В настоящее время ученые отмечают необходимость повседневной работы по формированию и развитию ведущих мотивов педагогической деятельности у всех членов педагогического коллектива (Ю.А. Конаржевский), использования воспитательных возможностей организации (Т.И. Шамова), оценочно - стимулирующей деятельности (И.М. Чередов), оптимального сочетания самоорганизации и управления (Е.А. Ямбург).

Предметом исследования Ю.А. Конаржевского, В.С. Лазарева, Н.В. Немовой, Ю.И. Рудиновой, Т.Э. Сизиковой, О.М. Симановской, Л.А. Церникель и других являются отдельные аспекты содержания мотивационного управления. Наиболее полный анализ разработанности проблем мотивационного управления образовательными системами сделан Л.А. Шипилиной. Исследователь освещает проблемы развития и использования человеческого фактора через применение средств и возможностей мотивационного менеджмента, выделяет основные понятия и теории мотивации в психологии, механизмы мотивации в управлении.

Раскрывая сущность мотивационного управления, исследователь уточняет это понятие, предлагает понимать его как механизм мотивирования и выделяет компоненты: цель, механизмы, результат, подчеркивает важность создания мотивационной среды, описывает правила, обеспечивающие положительную мотивацию. Ссылаясь на работы А.Г. Ковалева, И.К. Шалаева, исследователь считает мотивационное программно-целевое управление технологией мотивирования, в основе которой - действия, требующие осознания, обращенные к построению дерева целей, разработке исполняющей программы, отработке и реализации управляющей программы [11].

Поскольку мотивационный компонент является ведущим в структуре инновационной деятельности, то только мотивационное управление обеспечит гармоничное осуществление этой деятельности и самораскрытие личности преподавателя [5].

В таблице 1 представлены выделенные нами в процессе исследования факторы-мотиваторы инновационной деятельности преподавателей, описанные в научных исследованиях. 
Таблица 1. Факторы-мотиваторы инновационной деятельности преподавателей

\begin{tabular}{|c|c|}
\hline Авторы позиции & $\begin{array}{l}\text { Факторы-мотиваторы инновацион- } \\
\text { ной деятельности преподавателей }\end{array}$ \\
\hline $\begin{array}{l}\text { Н.В. Попкова, Е.А. Ямбург, В.С. Лаза- } \\
\text { рев, А.С. Сухоруков }\end{array}$ & $\begin{array}{l}\text { реализация идей самоуправления } \\
\text { и соуправления, сотрудничество в } \\
\text { педагогическом коллективе }\end{array}$ \\
\hline В.И. Андреев, В.И. Загвязинский & свободное творчество личности \\
\hline $\begin{array}{l}\text { В.М. Безруков, Ю.А. Конаржевский, } \\
\text { В.С. Лазарев }\end{array}$ & $\begin{array}{l}\text { разнообразие используемых моде- } \\
\text { лей содержания и форм организа- } \\
\text { ции образовательного процесса с } \\
\text { учетом потребностей, интересов и } \\
\text { склонностей его субъектов }\end{array}$ \\
\hline С.Б. Елканов, В.П. Кваша & $\begin{array}{l}\text { управление процессом самовос- } \\
\text { питания и саморазвития препода- } \\
\text { вателей }\end{array}$ \\
\hline $\begin{array}{l}\text { М.М.Поташник, 0.М. Симановская, } \\
\text { Т.И. Шамова }\end{array}$ & $\begin{array}{l}\text { сочетание волевых, социальных, } \\
\text { познавательных, эмоциональных } \\
\text { методов мотивации и стимулиро- } \\
\text { вания, методов управления мо- } \\
\text { тивацией самовыражения, само- } \\
\text { реализации в профессиональной } \\
\text { деятельности }\end{array}$ \\
\hline $\begin{array}{l}\text { Л.В. Алферова, Н.Ю. Ерофеева, Н.К. } \\
\text { Зотова }\end{array}$ & $\begin{array}{l}\text { система аттестации педагогических } \\
\text { и руководящих работников, само- } \\
\text { контроль, самоанализ, самооценка } \\
\text { уроков преподавателем }\end{array}$ \\
\hline $\begin{array}{l}\text { Г.Г. Габдуллин, В.И. Зверева, Т.М. } \\
\text { Куриленко }\end{array}$ & $\begin{array}{l}\text { организация всевозможных тре- } \\
\text { нингов, активно-игровых форм в } \\
\text { управлении школой, рефлексивно- } \\
\text { проектной деятельности препода- } \\
\text { вателей }\end{array}$ \\
\hline В.И. Андреев, Н.Ш. Чинкина & $\begin{array}{l}\text { компетентность руководителя, } \\
\text { его личностные качества, умелая } \\
\text { реализацию функций управления, } \\
\text { сформированность проектировоч- } \\
\text { но-прогностической деятельности } \\
\text { руководителя }\end{array}$ \\
\hline В.А. Сластенин, Т.И. Шамова & $\begin{array}{l}\text { деятельность заместителя дирек- } \\
\text { тора колледжа - инновационного } \\
\text { менеджера образования }\end{array}$ \\
\hline
\end{tabular}

Анализ исследований инноватики и менеджмента убедительно доказывает педагогическое, стимулирующее, научно-методическое влияние мотивационного управления на инновационную деятельность преподавателей.

Педагогическое влияние связано с «информационной деятельностью», обеспечивает взаимодействие членов педагогического коллектива, освоение ими конкретных профессиональных знаний и умений, осозна- ние, принятие нравственных норм служебного общения, актуализацию у них интереса к личному совершенствованию, формирование «внутренней самостоятельности преподавателя», «его стремления к самосовершенствованию» (С.Б. Елканов, В.И. Зверева, В.М. Шепель и др.).

Установление эмоционального контакта преподавателя и руководителя, ощутимые успехи в практическом овладении преподавателем более совершенными методами и приемами работы за счет активизаций методов управления, положительного примера самого руководителя, предъявления им разумных требований к людям обеспечивают стимулирующее и научно-методическое воздействия (Л.М. Митина, Н.В.Немова, Р.Х.Шакуров и другие).

Выделяя мотив стремления к успеху как самостоятельную мотивационную единицу, следует выделить эффективным методом построения общей ориентации на успех технологию проектирования поля успеха (Е.И. Казакова, А.П. Тряпицына). Сопровождаемое развитие является определенной альтернативой методу направляемого развития, а сопровождение рассматривается как комплексный метод, объединяющий четыре функции: диагностирование существа возникшей проблемы; информирование о существе проблемы и путях ее решения; консультирование на этапе принятия решения и выработки плана решения проблемы; первичная помощь на этапе реализации плана решений.

Из вышерассмотренного можно сделать вывод, что мотивационное управление инновационной деятельностью преподавателей - процесс, включающий совокупность взаимосвязанных методов, средств управления и условий, необходимых и достаточных для формирования мотивов саморазвития и самореализации в профессиональной деятельности преподавателя, т.е. как совокупность взаимосвязанных и взаимообусловленных структурных и функциональных компонентов, составляющих целостность, единство.

Авторы многих работ по управлению [4; 6; 7] считают развитие инновационных процессов содержанием деятельности руководителя колледжа. Ее особенности характеризуют логически построенным чередованием функций: информационно-аналитической, мотивационно-целевой, планово-прогностической, организационно-исполнительской, контрольно-диагностической, регулятивно-коррекционной, определяют приоритет видов деятельности в реализации каждой функции управления. В нашем исследовании рассматривается идея формирования инновационной деятельности преподавателей за счет усиления мотивационно-целевой функции управления. Непременным условием реализации этой функции в деятельности руководителя является опора на личностно ориентированную модель взаи- 
модействия участников образовательного процесса.

Анализ психолого-педагогической литературы [1; 5; 6] позволил нам среди ролей руководителя колледжа, напрямую связанных с выполнением мотивационной деятельности, выделить следующие: фасилитатор (проектировщик, консультант, организатор), методист (аналитик, прогнозист, программист), методолог (инноватор, коммуникатор, пропагандист), эксперт (диагност, контролер, оценщик).

Роль методолога является, на наш взгляд, ведущей, эталоном модели поведения для всех работников колледжа. Эта роль требует от руководителя колледжа активного диалога с преподавателями, работы по согласованию ценностей, по поиску общего понимания предназначения колледжа, путей его развития. «Методологические» способности нужны директору колледжа или его заместителям для реализации функции руководства, частью которой является мотивационная работа, направленная на развитие педагогического мировоззрения, ценностных ориентаций преподавателей, обучению их исследовательским умениям.

Исходя из анализа литературы по управлению и менеджменту, можно констатировать: для современного мотивационного управления колледжем характерной становится деятельность руководителя колледжа - менеджера первого уровня, направленная на создание нового видения социально-педагогических процессов, научно-методического обеспечения обновления и успеха всех преобразований, а мотивация выполняет функцию приводного ремня между работниками и организацией.

Таким образом, сложившиеся или специально организованные условия трудовой деятельности и взаимоотношений, которые обеспечивают усвоение в готовой форме побуждений, целей, идеалов, содержания направленности личности, определяют направленность и величину усилий, прилагаемых работниками для достижения целей организации, являются мотивационной средой и результатом мотивационного управления.

Проведенное нами исследование позволило выявить ряд компонентов мотивационного управления инновационной деятельностью преподавателей в условиях колледжа, которые представлены в таблице 2.
Таблица 2.

Компоненты мотивационного управления инновационной деятельностью преподавателей

$$
\text { в условиях колледжа }
$$

\begin{tabular}{|l|l|}
\hline Компонент & $\begin{array}{l}\text { Характеристика компонента мотивационного управ- } \\
\text { ления }\end{array}$ \\
\hline $\begin{array}{l}\text { мотивационно- } \\
\text { стимулирующий }\end{array}$ & $\begin{array}{l}\text { создание ситуации критической самооценки сред- } \\
\text { ствами аттестации педагогических работников }\end{array}$ \\
\hline $\begin{array}{l}\text { компетентностно- } \\
\text { развивающий }\end{array}$ & $\begin{array}{l}\text { активизация научно-методической поддержки и со- } \\
\text { провождения инновационных процессов, рекламы } \\
\text { педагогических инициатив и достижений, личност- } \\
\text { но-мотивированное сопровождение субъектного } \\
\text { опыта, проектирования и реализации инновацион- } \\
\text { ной деятельности преподавателей }\end{array}$ \\
\hline $\begin{array}{l}\text { организационно- } \\
\text { деятельностный }\end{array}$ & $\begin{array}{l}\text { совокупность действий руководителя, обеспечива- } \\
\text { ющих мониторинг учебно-методической работы и } \\
\text { экспертизу профессиональной компетентности пре- } \\
\text { подавателей в межаттестационный период }\end{array}$ \\
\hline
\end{tabular}

В соответствии с этим мотивационное управление предлагаем рассматривать как специфическую деятельность руководителя колледжа (менеджера образования), направленную на мотивирование преподавателей к инновационной деятельности, самореализации в профессиональной сфере.

Исследования, раскрывающие сущность и особенности мотивационного управления, на наш взгляд, могут быть успешно использованы для организации мотивационной среды, выступающей условием формирования и развития инновационной деятельности преподавателей.

Таким образом, теоретический анализ проблемы мотивационного управления инновационной деятельностью преподавателей колледжа показывает, что в большинстве исследований акцент сделан на выявлении социально-психологических факторов, составляющих конструктивную основу мотивационного программноцелевого управления, методах мотивирования (стимулирования), организационно педагогической деятельности руководителей, несколько меньшее внимание уделено рассмотрению способов и средств мотивирования в деятельности руководителей колледжа.

\section{ЛИТЕРАТУРА}

1. Ефимова Г.Н. Стратегическое управление как важнейшее условие обеспечения эффективного развития общеобразовательной организации // Региональное образование: современные тенденции. - 2017. - № 1 (31). - С. 24-28.

2. Кузнецов В.М., Соловьева Т.В., Трошков С.Н. Моделирование мотивационного управления инновационной деятельностью педагогов в условиях становления резильентной школы // Педагогический имидж. - 2018. - № 4 (41). - С.5-17.

3. Лазарева, В.С., Поташника, М.М., Управление развитием школы: пособие для руководителей образовательных учреждений. - М.: Новая школа. - 1995 462 c. 
4. Ландсберг, М. Дао мотивации. Вдохновляй себя и других / М. Ландсберг. - М.: Олимп-Бизнес, 2018. - 728с.

5. Мусуралиева А. Сущность и значение инноваций в управлении современной школой // Известия ВУЗов (Кыргызстан). - 2017. - № 4-1. - С. 52-54.

6. Мессмер М. Мотивация персонала для «чайников». - М.: Диалектика - Вильямс, 2017. - 305 с.

7. Нехвядович 0.В. Мотивационная готовность учителя к инновационной деятельности // Вестник Московского государственного областного университета. Серия: Педагогика. - 2016. - № 2. - С. 40-43.

8. Пономарев И.П. Мотивация работой в организации. - М.: Едиториал УРСС, 2015. - 224 с.

9. Шамова Т.И., Третьяков П.И., Капустин Н.П. Управление образовательными системами. - Учебное пособие для вузов. - М.: Владос, 2002 г. - 320 стр.

10. Шолохов А.В., Шлигель-Мильх А.В. Управление школой как системой и управление образовательным процессом в рамках модели инклюзивного образования // Вестник Таганрогского государственного педагогического института. - 2018. - № 1. - С. 123-128.

11. Шипилина Л.А. Методология и методы психолого-педагогических исследований: [электронный ресурс] учеб. пособие для аспирантов и магистрантов по направлению «Педагогика». - 3-е изд., стереотип. - М. :ФЛИНТА, 2011 - 204 с.

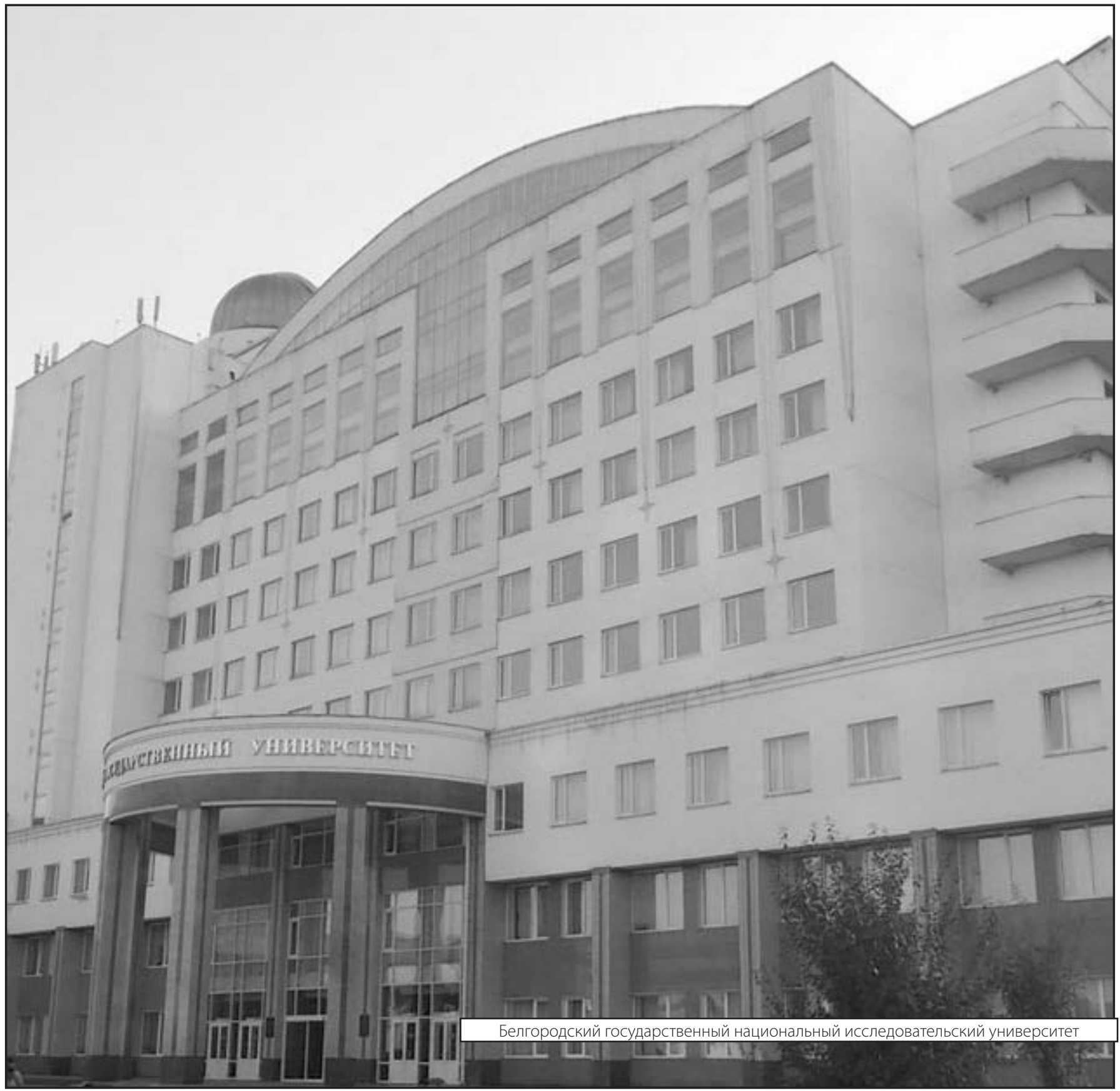

